\title{
Optimal trade-offs between energy efficiency improvements and additional renewable energy supply: A review of international experiences
}

\section{Baldini, Mattia; Klinge Jacobsen, Henrik}

Published in:

2016 13th International Conference on the European Energy Market (EEM)

Link to article, DOI:

10.1109/EEM.2016.7521245

Publication date:

2016

Document Version

Publisher's PDF, also known as Version of record

Link back to DTU Orbit

Citation $(A P A)$ :

Baldini, M., \& Klinge Jacobsen, H. (2016). Optimal trade-offs between energy efficiency improvements and additional renewable energy supply: A review of international experiences. In 201613 th International Conference on the European Energy Market (EEM) IEEE. https://doi.org/10.1109/EEM.2016.7521245

\section{General rights}

Copyright and moral rights for the publications made accessible in the public portal are retained by the authors and/or other copyright owners and it is a condition of accessing publications that users recognise and abide by the legal requirements associated with these rights.

- Users may download and print one copy of any publication from the public portal for the purpose of private study or research

- You may not further distribute the material or use it for any profit-making activity or commercial gain

- You may freely distribute the URL identifying the publication in the public portal 


\section{Optimal trade-offs between Energy Efficiency improvements and additional Renewable Energy supply: A review of international experiences}

\author{
Mattia Baldini \\ Technical University of Denmark (DTU) \\ Lyngby, Denmark \\ Email: mbal@dtu.dk
}

\author{
Henrik Klinge jacobsen \\ Technical University of Denmark (DTU) \\ Lyngby, Denmark \\ Email: jhja@dtu.dk
}

\begin{abstract}
Energy is a commodity used worldwide, representing a vital input for social and economic development. Due to continuous growth, energy demand has increased. Solutions have been proposed in order to satisfy the increase in demand, often implying the increase of capacity of the power mix. Meanwhile, current issues concerning climate change and fossil fuels depletion has moved attention towards cleaner ways to produce energy. This trend facilitated the breakthrough of renewable technologies. Since then, support policies have promoted the large deployment of renewables, without considering enough the improvements made in the energy saving field. Indeed, little attention has been paid to implement energy efficiency measures, which has resulted in scenarios where expedients for a wise use of energy (e.g. energy savings and renewables share) are unbalanced. The aim of this paper is to review and evaluate international experiences on finding the optimal trade-off between efficiency improvements and additional renewable energy supply. A critical review of each technique, focusing on purposes, methodology and outcomes, is provided along with a review of tools adopted for the analyses. The models are categorized and presented according to their main characteristics (e.g. bottomup/top-down model, regional/national analysis, partial/general equilibrium, static/dynamic model). The results of this paper provide, to the decision-makers, informations useful to identify a suitable analysis for investigate on the optimal trade-off between renewables and energy efficiency measures in energy-systems under different objectives.
\end{abstract}

\section{INTRODUCTION}

The enlargement of the energy sector in the past years brought a new problem since the green-house gases (GHG) emission related with energy production began to affect the environment, leading to global complications [1]. Various measurements and policies have been developed since then and, in vision of an international recognized effort, the Annex I countries signed the Kyoto Protocol in 1997 [2]. The recurrent issues concerning climate change and fossil fuels depletion has thus moved attention towards cleaner ways to produce energy. Among all, two valid solutions for reducing $\mathrm{CO}_{2}$ emissions have been identified as the most relevant: energy efficiency improvements (EE) and generation by renewable energy sources (RES) [3]. The European Commission already acknowledge the positive contribution of EE and RES policies in the fight against GHG emissions identifying the measures as "no regret options for transforming the energy system [4]" when analyzing future scenarios for the year 2030 [5]. In vision of a greener future, different studies have analyzed (with diverse goals and perspectives) the potential of implementing RES and EE in the energy systems [6]-[8]. Results often show that the implemented support policies have promoted large deployment of renewables, without considering enough improvements made in the energy saving field. Indeed, less attention has been paid to implement energy efficiency measures in energy systems modeling, which has resulted in scenarios where expedients for a wise use of energy (e.g. energy savings and RES' share) are unbalanced and cost-savings opportunities are missed [8]-[10]. The causes of this non-perfect scenarios are to be found in the interactions and integrations among these measures. Even though synergies among RES and energy efficiency are commonly acknowledged [11]-[14], the tradeoff among them is still an un-explored field. Many studies have been investigating on future energy systems based $100 \%$ on renewable sources [15]-[17], as well as scenarios where energy efficiency measures contributes to GHG reduction and reduce energy demand [18]-[20]. However, just few studies have been focusing on the simultaneous implementation of policies regarding EE and RES in energy systems models and analyze their trade off. The aim of this paper is to review and evaluate the international experiences on the integration of energy efficiency measures and additional RES supply in the energy system. The screened studies have been analyzed focusing on the different techniques, purposes, methodology and outcomes. Moreover, the tools used for the analyses have been categorized and presented according to their main characteristics. The article aims at being useful as: starting point for those not familiar with the topic, benchmark for authors who already deals with it, and as a guidance for decision makers in the process of identifying a suitable analysis to investigate on the optimal trade-offs under different objectives. The article is structured as follows: Section II refers to the classification of the models and the studies selected. In Section III the categories previously introduced are used as a starting point to discuss the classification provided. Section IV summarize on the findings, concludes on the topic and suggests future 
development on the matter.

\section{ClassificAtion OF THE STUdies ACCORDing TO THE CATEGORIES}

Before starting the analysis, a clarification is reported on the difference between synergy and trade off, energy efficiency and energy savings since the terms are often misconceived. There can be synergy between two factors when their combined effect is greater (or smaller) than the sum of their separate effects [21]; on the other hand the trade-off refers to a method of reducing or forgoing one or more desirable outcomes in exchange for increasing or obtaining other desirable outcomes in order to maximize the total return or effectiveness under given circumstances [22]. Furthermore energy efficiency refers to the technical ratio between the quantity of primary or final energy consumed and the maximum quantity of energy service obtainable (heating, lighting, cooling,...), while energy savings implies the reduction of final energy consumption, through energy efficiency improvements or behavioral change [23]. For the trade-off investigation, both energy savings and energy efficiency concepts were considered.

\section{A. Models}

The tools adopted in the different analyses cover a wide range of characteristics. Those considered most relevant were used to categorize the models. The focus of the analysis will thus be on the analytical and mathematical approach selected when formulating the problem and writing the equations, on the type of resulting equilibrium and on the interfacing with the model's runtime (i.e. dynamicity). The results are reported in Table I where the models are listed in order of appearance in the studies presented in Table II (i.e. ENPEP-BALANCE is used in [24], MASTER.SO in [8], and so on...). Plenty of other models' features could be investigated and discussed. However, the aim of this section is not to report a full and complete description of the models along with their features, but rather to highlight the most relevant for the paper. For a thorough description of the models investigated, readers can refer to reviews about energy system models [25]-[28].

\section{B. Breaking down the studies}

Despite the fact that some authors used the same model to perform the studies (e.g. MARKAL for studies [9], [10]), the reasons for the investigations were different. Therefore, the studies were analyzed according to selected criteria: purpose of the study, methodology, results evaluation and conclusions of the studies. The results are reported in Table II. The intention of the categorization is to:

- investigate on the reasons of the studies

- understand the methodology towards the final goal

- highlight the different ways to evaluate the results

- discuss and reflects on the final findings.

The findings are used for the discussion that follows, where results are then examined identifying common characteristics.
Table I

ANALYSIS OF THE TOOLS

\begin{tabular}{ccccc}
\hline Tool & $\begin{array}{c}\text { Analytical } \\
\text { approach }\end{array}$ & $\begin{array}{c}\text { Mathematical } \\
\text { approach }\end{array}$ & Equilibrium & Model \\
\hline ENPEP - & Top-down & Non linear & Yes & - \\
BALANCE [29] & & & & \\
MASTER.SO [30] & Bottom-up & Linear & Partial & Static \\
IOCM [31] & Bottom-up & Linear & Yes & Static \\
EnergyPLAN - & Bottom-up & Linear & Partial & Static \\
GenOpt [32] & & & & \\
Remap 2030 [33] & Spreadsheet & - & Yes & - \\
PRIME 2007 [34] & Top-down & Non linear & Partial & Static \\
MESSAGE [35] & Hybrid & Linear & Partial & Dynamic \\
MARKAL - & Bottom-up & Linear & Yes & Dynamic \\
TIME [36] & & & & \\
MARKAL [36] & Bottom-up & Linear & Yes & Dynamic \\
MDDH [37] & Bottom-up & Linear & Yes & Dynamic \\
TIMES [38] & Bottom-up & Linear & Partial & Static \\
IRP [39] & Bottom-up & Linear & Partial & Static \\
IRSP [40] & Bottom-up & Non linear & Partial & Static \\
IRSP [41] & Bottom-up & Non linear & Partial & Static \\
& & & &
\end{tabular}

\section{OUTCOMES: COMPARISON AND ASSESSMENT}

\section{A. Models}

Following the categorization reported in Table I the results are here commented. A common factor that joins together all models is the optimization methodology, certainly related to the nature of the final goals of each analysis. Only one model (MDDH) deals with stochasticity. The reasons being that the model deals with an electrical power system with strong hydro generation, thus requiring stochastic techniques to deal with the uncertainties in the water-streamflows [37], [46]. Most of the models are bottom-up, one is hybrid (i.e. combines both top-down and bottom-up approach) and two are top-down. Usually, models referred as top-down emphasize economywide features, while bottom-up focus more on sectorial and technological details. The choice of bottom-up models for the analyses is thus in line with the goal of most of the research questions: investigating possible configurations of future energy systems. Depending on the degree of complexity of the analysis on the objective to optimize, the models were classified as linear and non linear. While the theoretical difference among the two methods is commonly acknowledged, it was found that those models which presented non linearity were either considering a multi-objective optimization approach [40], [41], considering non-linear cost supply curves of resources used in power generation [12] or including non linear modules while solving the optimization [24](e.g. BALANCE module for ENPEP [29]). The models are also classified according to the feature of static or dynamic modelling, where the main difference lies in the fact that a dynamic model is, in general, a model describing the state evolution of a system over time while a static model has a time independent view 
Table II

ANALYSIS OF THE STUDIES REVIEWED

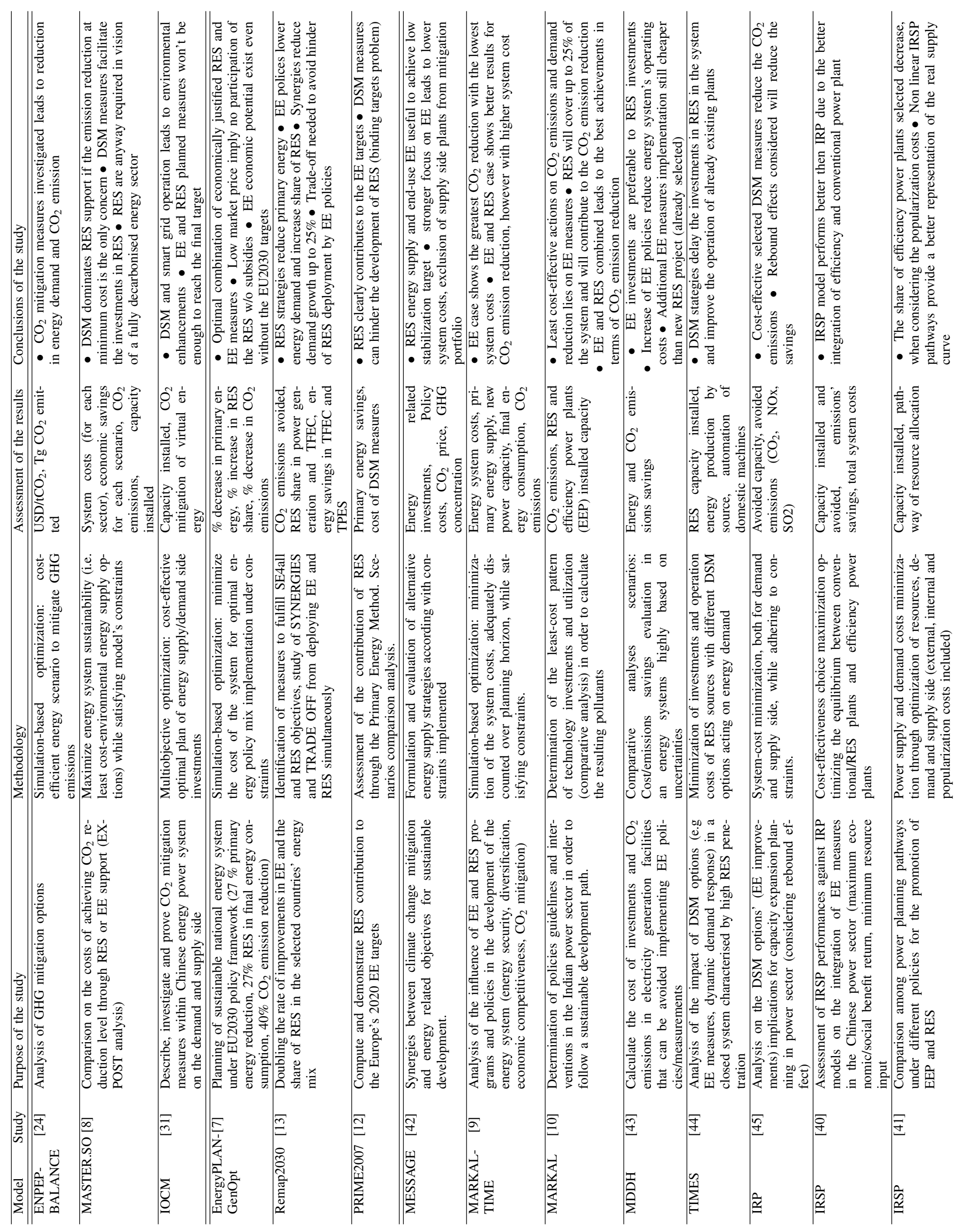


of a system [47]. Among all the models considered, only MARKAL, MESSAGE and MDDH considered a dynamic mathematical approach; all the other, for a matter or simplicity, considered a static approach. Concerning the final equilibrium in the markets, the tools can be categorized according to the level of inspection. When the aim is to investigate the changes in a particular sector without considering the interaction of this last with the whole system then the model will be classified as partial equilibrium. On the other hand, a model will be labeled as general equilibrium if the assumption is that every market has an effect on every other market and therefore a change in one market may result in changes in another market. A close observation of the results reported in Table I shows that there is a fair split between the two categories, thus implying that half of the studies has been focusing entirely on a sector (i.e. energy sector), while the others investigated the goals considering the changes in different sectors and the interactions among them.

\section{B. Studies}

The studies selected were investigated according to the selected criteria previously introduced. The resulting considerations from the results in Table II are here remarked. The purposes can be divided in three categories: (1) $\mathrm{GHG} / \mathrm{CO}_{2}$ mitigation options investigation, (2) targets fulfillment study and (3) analysis of policies and programs development. According to this division, the studies [8], [24], [31] belongs to the first category, [7], [12], [13] to the second, while the remaining to the third (see Table II). Concerning the technique adopted, due to the nature of the models and the way the problems were mathematically formulated, almost all the studies follow the "system operation/investments-cost minimization while adhering to constraints" approach. Besides, the policies objectives are implemented as constraints on the different variables under investigation. The results of the analysis are assessed with different indicators, usually related with the focus of the analysis. Among the most employed there are: decrease in primary energy (due to energy savings), increase in RES share, $\mathrm{CO}_{2}$ emission levels, new capacity investments as well as policy cost, cost of emission reduction, energy system costs, economic savings and $\mathrm{CO}_{2}$ avoided. Regarding the conclusions of the studies, the findings point to similar outcomes. Among the most supported, there are the following:

- EE measures are the most cost-effective options for $\mathrm{CO}_{2}$ reduction in energy systems

- EE measures should be implemented first, RES after

- RES energy supply and end-use EE is the best combination to achieve low system energy costs and high $\mathrm{CO}_{2}$ reduction (however, with higher system prices)

- Synergies between RES and EE are commonly acknowledged, while trade-offs are still well not defined

- Attention must be paid to the rebound effect since it can decrease the savings (economic, energy and emissions)

- EE measures imply popularization costs (necessary to spread the knowledge) that can hinder their development.

In support, an analysis performed on the Spanish sector [8], reported that if the reduction of emissions at a minimum cost is the only concern, implementing EE measures would led to almost 5 mil€of savings (both in RES promotion and to meet the reduced demand). Moreover, on the interaction between EE-RES, the EE measures can act both positively and negatively. In the short term, the increase of EE measures leads to a decrease of the energy demand, thus increasing the share of RES in the system and fostering their use [48]. In the long term, the additional measures towards efficiency hinder and delay RES deployment, since the reduced energy demand is already covered by a well balanced energy system [12], [44]. Different studies have already acknowledge the significance of the rebound effect and popularization costs when analyzing EE implementation in energy systems [49]-[51]. The magnitude is usually estimated in a range between $0 \%$ and $30 \%$ (rebound) [52] and 20\% (popularization) [41] of the savings gained, thus making both of them essential factors to consider in analyses of energy system highly based on EE. Nevertheless, a proper mix of measures on both demand and supply is necessary in order to gain significant emission reduction [53]. Hence both EE and RES are necessary. The challenge then is to coordinate support policies in order to achieve the desired result at the lowest cost.

\section{CONCLUSiOnS}

When planning future development of the energy system it is important to focus on the trade off between energy efficiency improvements and additional renewable energy supply. The reasons lies on economical and environmental benefits that can be gained by such investigation. The trade-off can be found to be different from system to system depending on the structure of the already existing energy system, on the availability of RES sources/EE measures and on the potential of implementation of such. Thus contextualization is an important factor when comparing different trade-offs outcomes. The goal of the paper was to analyze studies that investigated on the trade-off between RES and EE. The selected studies along with the models used were split in categories. The features of the tools were found to be different according to the kind of investigation performed. Concerning the studies, the analysis highlighted that the purposes could be gathered in three categories $\left(\mathrm{GHG} / \mathrm{CO}_{2}\right.$ mitigation options investigation, targets fulfillment study and analysis of policies development). Moreover, all the studies point toward a path of integration between RES and EE measures. A trade-off is nonetheless necessary in order not to hinder the development of the RES. Finally, just few studies were found to be focusing entirely on finding the optimal trade-off, highlighting the lack of examples in the literature about the topic. Questions like "what should be the share of RES and EE in the system, given a pre-defined goal" and "which technologies/measures are more suitable to cover the share for each system" should be answered by these kind of studies. Future works of future modelers should thus strength the focus on finding the trade-off (RES-EE) for each of the investigated systems. The results of these analysis will lead to shape future energy systems towards configurations where expedients for a wise use of energy will be balanced. 


\section{REFERENCES}

[1] IPCC, "Climate Change 2014 Synthesis Report Summary Chapter for Policymakers," Ipcc, 2014.

[2] Unfccc, "Kyoto Protocol To the United Nations Framework Kyoto Protocol To the United Nations Framework," Review of European Community and International Environmental Law, 1998.

[3] P. Ekins, "Step changes for decarbonising the energy system: research needs for renewables, energy efficiency and nuclear power," Energy Policy, 2004.

[4] European Commission, "Green Paper - A 2030 framework for climate and energy policies," 2012.

[5] I. M. de Alegría Mancisidor, P. Díaz de Basurto Uraga, I. Martínez de Alegría Mancisidor, and P. Ruiz de Arbulo López, "European Union's renewable energy sources and energy efficiency policy review: The Spanish perspective," Renewable and Sustainable Energy Reviews, 2009.

[6] P. Del Río, "Analysing the interactions between renewable energy promotion and energy efficiency support schemes: The impact of different instruments and design elements," Energy Policy, 2010.

[7] N. Rajakovi, "Simulation-based optimization of sustainable national energy systems," 2015.

[8] Á. López-Peña, I. Pérez-Arriaga, and P. Linares, "Renewables vs. energy efficiency: The cost of carbon emissions reduction in Spain," Energy Policy, 2012.

[9] V. Taseska-Gjorgievska, A. Dedinec, N. Markovska, G. Kanevce, G. Goldstein, and S. Pye, "Assessment of the impact of renewable energy and energy efficiency policies on the Macedonian energy sector development," Journal of Renewable and Sustainable Energy, 2013

[10] S. Mallah and N. Bansal, "Renewable energy for sustainable electrical energy system in India," Energy Policy, 2010.

[11] P. Hennicke, S. Thomas, and W. Irrek, "Towards Sustainable Energy Systems: Integrating Renewable Energy and Energy Efficiency is the Key," Discussion paper for Renewables 2004 International Conference, Wuppertal / Eschborn, May 2004, 2004.

[12] R. Harmsen, B. Wesselink, W. Eichhammer, and E. Worrell, "The unrecognized contribution of renewable energy to Europe's energy savings target," Energy Policy, 2011.

[13] IRENA, "Synergies between renewable energy and energy efficiency. A working paper based on REMAP 2030," 2015.

[14] T. M. Lenard, "Renewable Electricity Standards, Energy Efficiency, and Cost-Effective Climate-Change Policy," Electricity Journal, 2009.

[15] H. Lund and B. Mathiesen, "Energy system analysis of $100 \%$ renewable energy systemsThe case of Denmark in years 2030 and 2050," Energy, 2009.

[16] G. Krajačić, N. Duić, Z. Zmijarević, B. V. Mathiesen, A. A. Vučinić, and M. da Graça Carvalho, "Planning for a $100 \%$ independent energy system based on smart energy storage for integration of renewables and CO2 emissions reduction," Applied Thermal Engineering, 2011.

[17] D. Connolly, H. Lund, B. Mathiesen, and M. Leahy, "The first step towards a 100\% renewable energy-system for Ireland," Applied Energy, 2011.

[18] T. J. Brennan, "Optimal energy efficiency policies and regulatory demand-side management tests: How well do they match?" Energy Policy, 2010.

[19] K. Gillingham, R. G. Newell, and K. Palmer, "Energy Efficiency Economics and Policy," Discussion paper, 2003.

[20] J. Tao and S. Yu, "Implementation of energy efficiency standards of household refrigerator/freezer in China: Potential environmental and economic impacts," Applied Energy, 2011.

[21] J. Luukkanen, J. Vehmas, F. Allievi, J. Panula-Ontto, and J. Kaivo-oja, "Synergies and trade-offs between unsustainable trends identified in the European Union- Empirical analysis carried out with the advanced sustainability analysis (ASA) approach," Research Report. Finland Futures Research Centre. University of Tampere. Tampere, 2006.

[22] BusinessDictionary.com, "Business Dictionary," 2014. [Online]. Available: http://www.businessdictionary.com/definition/tradeoff.html

[23] V. Oikonomou, F. Becchis, L. Steg, and D. Russolillo, "Energy saving and energy efficiency concepts for policy making," Energy Policy, 2009.

[24] C. Christov, K. Simeonova, S. Todorova, and V. Krastev, "Assessment of mitigation options for the energy system in Bulgaria," Applied Energy, 1997.

[25] D. Connolly, H. Lund, B. Mathiesen, and M. Leahy, "A review of computer tools for analysing the integration of renewable energy into various energy systems," Applied Energy, 2010.
[26] F. Urban, R. Benders, and H. Moll, "Modelling energy systems for developing countries," Energy Policy, 2007.

[27] R. Pandey, "Energy policy modelling: agenda for developing countries," Energy Policy, 2002.

[28] N. V. Beeck, "Classification of Energy Models," Tilburg University \& Eindhoven University of Technology, 1999.

[29] G. Conzelmann, "Greenhouse Gas Mitigation Analysis Using ENPEP," International Atomic Energy Agency, 2001.

[30] Á. López-Peña, P. Linares, and I. Pérez-Arriaga, "MASTER.SO: a Model for the Analysis of Sustainable Energy Roadmaps. Static Optimisation version," 2013

[31] P. Dai, G. Chen, H. Zhou, M. Su, and H. Bao, "CO(2) Mitigation Measures of Power Sector and Its Integrated Optimization in China." TheScientificWorldJournal, 2012.

[32] Aalborg University, "EnergyPLAN. Advanced energy systems analysis computer model," 2016. [Online]. Available: http://www.energyplan.eu/

[33] Irena, "A Renewable Energy Roadmap," Tech. Rep. June, 2014.

[34] National Technical University of Athens, "The PRIMES Energy System Model. Summary Description," Tech. Rep.

[35] International Institute for Applied Systems Analysis, "MESSAGE IIASA." [Online]. Available: http://www.iiasa.ac.at/web/home/research/ researchPrograms/Energy/MESSAGE.en.html

[36] R. Loulou, G. Goldstein, and K. Noble, "Documentation for the MARKAL Family of Models," 2004.

[37] B. H. Dias, A. L. M. Marcato, R. C. Souza, M. P. Soares, I. C. Silva Junior, E. J. D. Oliveira, R. B. S. Brandi, and T. P. Ramos, "Stochastic dynamic programming applied to hydrothermal power systems operation planning based on the convex hull algorithm," Mathematical Problems in Engineering, 2010.

[38] Energy Technology System Analysis Program (ETSAP), "TIMES." [Online]. Available: http://www.iea-etsap.org/web/Times.asp

[39] N. T. Nguyen and M. Ha-duong, "The potential for mitigation of $\mathrm{CO} 2$ emissions in Vietnam s power sector," 2009.

[40] Z. Hu, X. Tan, F. Yang, M. Yang, Q. Wen, B. Shan, and X. Han, "Integrated resource strategic planning: Case study of energy efficiency in the Chinese power sector," Energy Policy, 2010.

[41] J. Yuan, Y. Xu, J. Kang, X. Zhang, and Z. Hu, "Nonlinear integrated resource strategic planning model and case study in China's power sector planning," Energy, 2014.

[42] O. van Vliet, V. Krey, D. McCollum, S. Pachauri, Y. Nagai, S. Rao, and K. Riahi, "Synergies in the Asian energy system: Climate change, energy security, energy access and air pollution," Energy Economics, 2012.

[43] R. F. Calili, R. C. Souza, A. Galli, M. Armstrong, and A. L. M. Marcato, "Estimating the cost savings and avoided $\mathrm{CO} 2$ emissions in Brazil by implementing energy efficient policies," Energy Policy, 2014.

[44] A. Pina, C. Silva, and P. Ferrão, "The impact of demand side management strategies in the penetration of renewable electricity," Energy, 2012.

[45] R. M. Shrestha and C. O. P. Marpaung, "Integrated resource planning in the power sector and economy-wide changes in environmental emissions," Energy Policy, 2006.

[46] R. C. Souza, A. L. M. Marcato, B. H. Dias, and F. L. C. Oliveira, "Optimal operation of hydrothermal systems with Hydrological Scenario Generation through Bootstrap and Periodic Autoregressive Models," European Journal of Operational Research, 2012.

[47] B. Apolloni, A. Ghosh, F. Alpaslan, L. C. Jain, and S. Patnaik, Machine Learning and Robot Perception, Springer, Ed., 2005.

[48] A. C. Marques and J. a. Fuinhas, "Do energy efficiency measures promote the use of renewable sources?" Environmental Science and Policy, 2011.

[49] S. Sorrell, J. Dimitropoulos, and M. Sommerville, "Empirical estimates of the direct rebound effect: A review," Energy Policy, 2009.

[50] R. Madlener and B. Alcott, "Energy rebound and economic growth: A review of the main issues and research needs," Energy, 2009.

[51] L. A. Greening, D. L. Greene, and C. Difiglio, "Energy efficiency and consumption - the rebound effect - a survey," Energy Policy, 2000.

[52] R. Madlener and M. Hauertmann, "Rebound Effects in German Residential Heating: Do Ownership and Income Matter?" FCN Working Paper, 2011.

[53] B. Ćosić, N. Markovska, V. Taseska, G. Krajačić, and N. Duić, "The potential of GHG emissions reduction in Macedonia by renewable electricity," Chemical Engineering Transactions, 2011. 